Original Research Paper

\title{
Dialectic Form Finding of Structurally Integrated Adaptive Structures
}

\author{
${ }^{1}$ L. Rhode-Barbarigos, ${ }^{2}$ V. Charpentier, ${ }^{2}$ S. Adriaenssens and ${ }^{3}$ O. Baverel \\ ${ }^{I}$ Department of Civil, Architectural and Environmental Engineering, University of Miami, Coral Gables FL, USA \\ ${ }^{2}$ Form Finding Lab, Department of Civil and Environmental Engineering, Princeton University, Princeton NJ, USA \\ ${ }^{3}$ Laboratoire Navier/Géométrie Structure Architecture, Ecole des Ponts ParisTech, Paris, France
}

\author{
Article history \\ Received: 26-06-2015 \\ Revised: 27-06-2015 \\ Accepted: 30-06-2015 \\ Corresponding Author: \\ L. Rhode-Barbarigos \\ Department of Civil, Architectural \\ and Environmental Engineering, \\ University of Miami, Coral Gables \\ FL, USA \\ Email: landolfrb@miami.edu
}

\begin{abstract}
Structural engineering, prompted by advances in mechanics and computing as well as design principles such as sustainability and resilience, is evolving towards adaptive structures. Adaptive structures are structures that use active components to change shape and properties in response to their environment and/or to their users' desires. Form-found structures, such as tensegrity and shell structures, can be designed to accommodate such changes within their structural behavior. Dialectic form finding is an extension of the traditional form-finding process integrating performance-related constraints and criteria in the search of a geometry in static equilibrium. Two examples of dialectic form-found structurally integrated adaptive structures are presented. The first example is a shape-shifting tensegrity-inspired structure, while the second example is a shapeshifting shell structure. Both systems are designed to explore elastic deformations for shape changes reducing actuation requirements and highlighting the potential of the proposed method.
\end{abstract}

Keywords: Adaptive Structures, Form-Finding, Analysis, ShapeChanging, Tensegrity, Shell

\section{Introduction}

The idea of adaptive structures can be found on the first manmade tents and temporal shelters. However, the origin of the concept is attributed to kinetic architecture. Kinetic architecture was first introduced by Zuk and Clark (1970) as "form may change very slowly by evolution, moderately fast by the process of growth and decay and very fast by internal muscular, hydraulic, or pneumatic action". An overview of kinetic architecture can be found in (Fox and Kemp, 2009). Although kinetic architecture has been focusing on adaptive structures mostly for movable and shape/space-changing applications, structural engineering has been identifying them as a potential solution to safety and serviceability design problems (Yao, 1972; Housner et al., 1997). The origin of adaptive structures in structural engineering can be attributed to Yao (1972) who introduced the concept of structural control as an alternative approach to safety problems. However, nowadays adaptive structures are employed for applications that span beyond safety, as structural control against long return-period phenomena is not widely accepted due to cost and reliability issues (Housner et al., 1997; Domer and Smith, 2005). An extensive review of structural control applications can be found in (Korkmaz, 2012).

Adaptive structures were first defined as structures that include both passive and active load-bearing elements (Soong and Manolis, 1987). Wada and Das (1991), who proposed a generalized framework based on various levels of structural control, defined them as structures that include actuators that allow them to change state or characteristics in a controlled manner. Movable and shape-shifting/deployable structures can thus be classified as adaptive structures that can perform large shape changes (Gantes, 2001; Pellegrino, 2001). A more recent definition was given 
by Sobek and Teuffel (2002) describing them as systems with the ability to manipulate their internal force distribution or influence their external loads over time. Elements that change length, such as active struts or active cables, have thus been extensively studied for the design and control of adaptive and active structures (Korkmaz, 2012). Nevertheless, the design of adaptive structures remains a challenging task due to the lack of universal methods for the integration and control of active elements. Moreover, active elements and control are often added to the structure after its design has been completed. Therefore, they are cannot be considered as structurally integrated. There are only few examples where the design of the structure and the control system were carried out simultaneously ( $\mathrm{Lu}$ and Skelton, 1998; Aldrich et al., 2003; Adriaenssens and Ney, 2007; Thrall et al., 2012a; 2012b).

In this study, dialectic form finding is explored as strategy for the design and analysis of structurally integrated adaptive structures. Through the paradigm of a tensegrity and a shell structure, it is shown that formfound structures can be designed to accommodate adaptation within their structural behavior. They are thus efficient both structurally as well as from an actuation perspective. The remainder of this paper is organized as follows: In section 2, the concept of dialectic formfinding is introduced. In Sections 3 and 4, the approach is applied on a tensegrity structure and a shell structure, respectively. Conclusions and further discussion are presented in section 5 .

\section{Dialectic form finding}

Form finding traditionally describes the forward process in which parameters, such as topology and support conditions, are controlled to find a geometry which is in static equilibrium with a specific set of design loads (Adriaenssens et al., 2014a). As a result, the obtained structures exhibit material and structural efficiency. Numerical form-finding methods include methods such as the force density (Schek, 1974), thrust network analysis (Block, 2009), dynamic relaxation (Barnes, 1999) and non-linear Finite Element (FE) approaches (Pagitz and Mirats Tur, 2009). Extensive reviews of form-finding methods can be found in (Tibert and Pellegrino, 2003; Veenendaal and Block, 2012; Adriaenssens et al., 2014b). In this study, numerical form-finding methods are combined with shape and structural behavioral constraints to develop adaptive structures that integrate active elements within their structural system. This approach is referred to as dialectic form finding (Adriaenssens et al., 2014b) and is illustrated in Fig. 1.

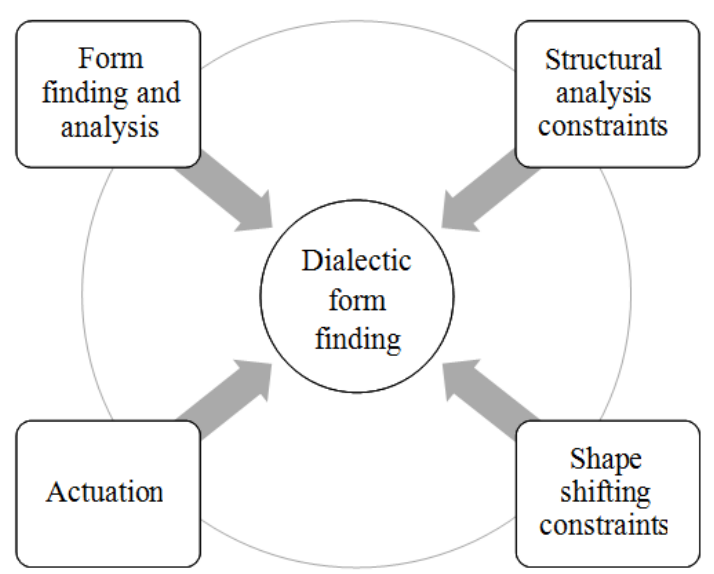

Fig. 1. Illustration of the dialectic form-finding approach and its components

Dialectic form finding describes an iterative process with four components: Form finding and analysis, structural analysis constraints, shape shifting constraints and actuation. The process starts with a statically stable configuration where actuation (element elongation or external load) is applied. A form finding and analysis method is employed to identify a new intermediate equilibrium configuration. The new configuration is then checked for structural performance and shape compliance depending on the system and application in question. If there is a constraint violation, a new configuration can be found by adapting the actuation applied. However, in case that modifying the actuation applied has little or no effect in the constraint violation or does not allow the desired shape transformation, the initial design should be re-examined and modified. If all constraints are satisfied, the process continues with a new actuation and the identification of a new equilibrium configuration. Under the assumption of quasi-static actuation, shape/state transformations are thus based on a series of intermediate form-found stable equilibrium configurations.

\section{A Structurally Integrated Adaptive Tensegrity Structure}

Tensegrity structures are defined as spatial reticulated structures composed of elements with unilateral and bilateral rigidity (Motro, 2006). Elements are combined in a self-equilibrated pre-stressed state that provides stability and stiffness to the structure. The tensegrity concept exists for almost 60 years now and has received significant interest from scientists and engineers (Munghan and Abel, 2011; Rhode-Barbarigos et al., 2012a; Ingber et al., 2014; Kim et al., 2014) especially for adaptive/shape-changing applications as actuators 
and structural elements can be combined (structurally integrated actuation) (Adam and Smith, 2008; Veuve et al., 2015). Tensegrity structures have been traditionally developed and analyzed using formfinding methods in which bilateral rigidity elements are modeled as truss elements (elements experiencing tension or compression). However, in reality tensegrity elements sustain also some bending. Bending might be negligible compared to the axial forces if it originates from dead load, but it might become critical if imperfections such as initial curvature or eccentricities are present (Rhode-Barbarigos and Adriaenssens, 2014). However, if designed appropriately, tensegrity structures can actually benefit from bending similar to other bending-active systems (Lienhard et al., 2011a).

The tensegrity structure employed in this paradigm is the simplex module (Motro, 2006). The simplex is composed of three struts and nine cables (Fig. 2). Dynamic relaxation is employed to investigate the actuation requirements (number of active elements) for folding and unfolding as well as the structural response of the module throughout shape transformations. Dynamic relaxation is an explicit numerical form-finding and analysis method of tensile structures (Day, 1965; Adriaenssens 2008; Ali et al., 2011; Richardson et al., 2013; Siu et al., 2013; Segal et al., 2015;) that avoids stiffness-matrix calculations (Brew and Brotton 1971) exploring the fact that the static solution for a structure subject to loading is the steady state of a step-force damped vibration. In this study, the spline-element formulation by Adriaenssens and Barnes (2001) is employed in the dynamic relaxation scheme to study elastic deformations due to bending.

In order to investigate the effect of bending action in the module, elements are first modeled using truss elements (purely axially loaded elements) and then using spline elements (initially straight elements that are actively bent). In order to initiate bending numerically in the spline elements, an initial curvature $1 / l_{s, e}$, where $l_{s, e}$ is the spline-element length, is given to the elements. Cables are made of stainless steel while trusses and splines are composed of Carbon Fiber Reinforced Polymer (CFRP). CFRP is chosen for its low Young modulus and high bending strength that allow the exploration of active bending deformations (Lienhard, 2014). The geometrical and material properties of the tensegrity module are given in Table 1.

In this study, cable-length changes are employed to fold and unfold the module. Changing cable lengths allows passing from one equilibrium configuration to another using finite mechanisms, while ensuring stability and stiffness (Rhode-Barbarigos et al., 2012b). The module has a height of $1 \mathrm{~m}$ and a width of $0.87 \mathrm{~m}$. To fold the simplex to half of its height, the length of horizontal cables has to increase while the length of vertical cables has to decrease. To unfold the module, the length of vertical cables has to increase while the length of horizontal cables has to decrease. Consequently, length changes (and thus actuation) in all nine cables of the module are required to change its shape. Moreover, boundary nodes must allow the required in-plane movement. They are thus are assumed blocked only along the vertical axis of the module. Figure 3 shows three side-view snapshots of the shape transformation of the tensegrity module with heights of $0.825,0.75$ and $0.625 \mathrm{~m}$ respectively.

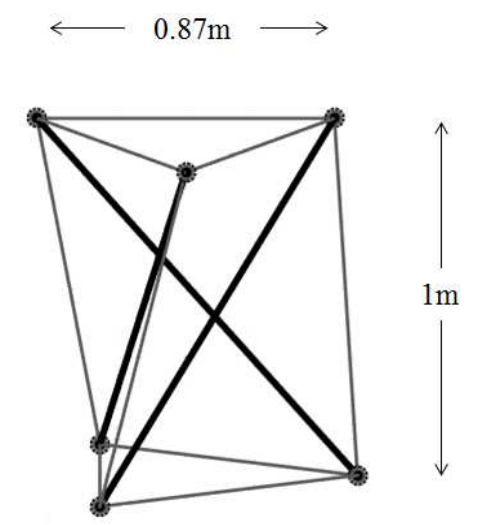

Fig. 2. Illustration of the simplex module with 3 struts (bold lines) and 9 cables (thin lines)

Table 1. Geometrical and material properties of the tensegrity modul

\begin{tabular}{|c|c|c|}
\hline Element & Property & Value \\
\hline \multirow[t]{4}{*}{ Cable } & Length L (m) & 0.87 and 1.39 \\
\hline & Tensile strength $\sigma_{\mathrm{x} \max }\left(\mathrm{N} / \mathrm{mm}^{2}\right)$ & 1096.5 \\
\hline & Cross-sectional area $\mathrm{A}\left(\mathrm{mm}^{2}\right)$ & 28.27 \\
\hline & Young's modulus E (N/mm²) & $115^{\prime} 000$ \\
\hline \multirow[t]{7}{*}{ Truss/spline } & Length L (m) & 1.4 \\
\hline & Tensile strength $\sigma_{\mathrm{x} \max }\left(\mathrm{N} / \mathrm{mm}^{2}\right)$ & 2100 \\
\hline & Compression strength $\sigma_{\mathrm{c} \max }\left(\mathrm{N} / \mathrm{mm}^{2}\right)$ & 700 \\
\hline & Bending strength $\sigma_{\mathrm{b} \max }\left(\mathrm{N} / \mathrm{mm}^{2}\right)$ & 2100 \\
\hline & Diameter D (mm) & 76.1 \\
\hline & Thickness $\mathrm{t}(\mathrm{mm})$ & 4 \\
\hline & Young's modulus E (N/mm²) & $40 ’ 000$ \\
\hline
\end{tabular}



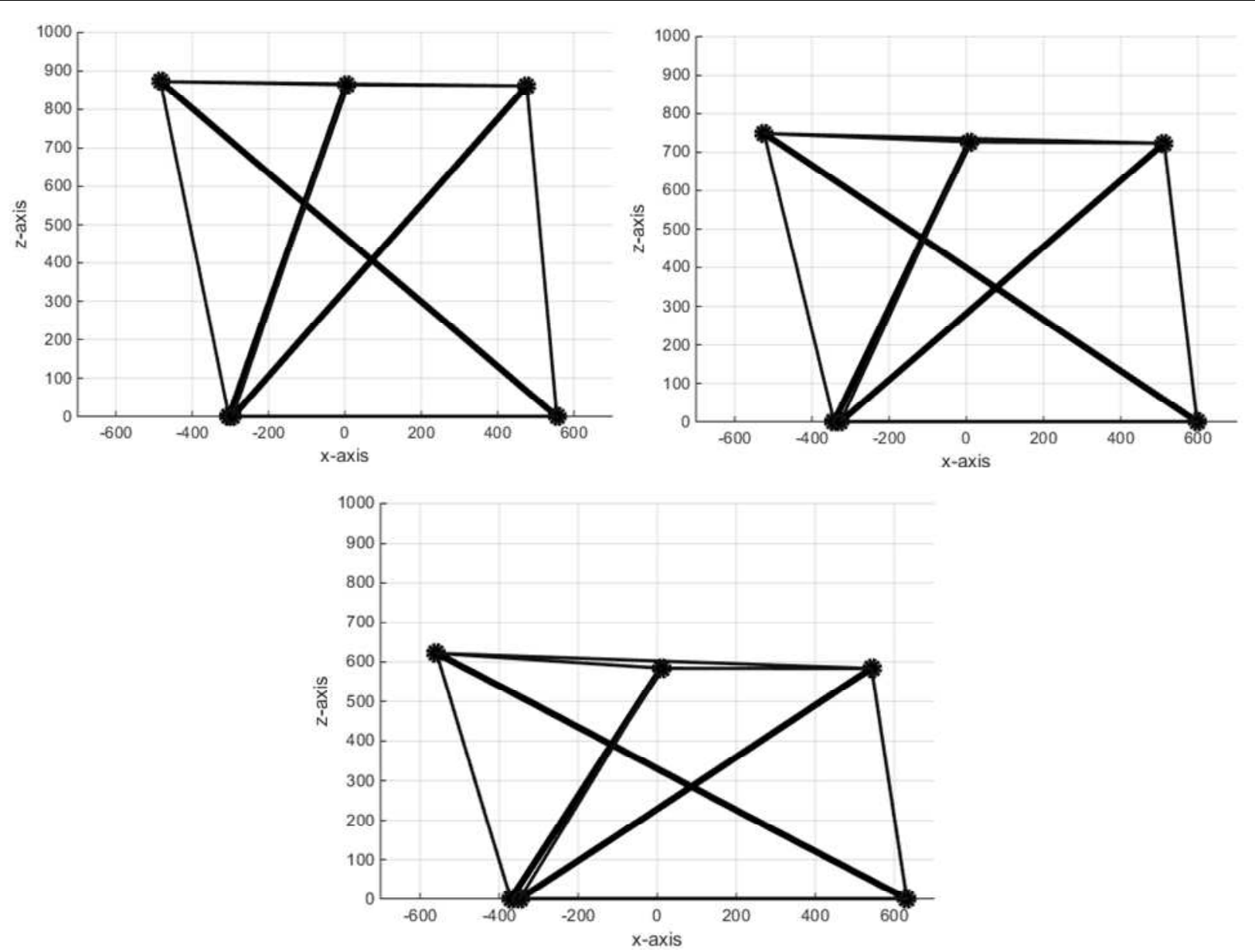

Fig. 3. Side-view snapshots of the shape transformation of the tensegrity module with finite mechanisms assuming strut and cable elements

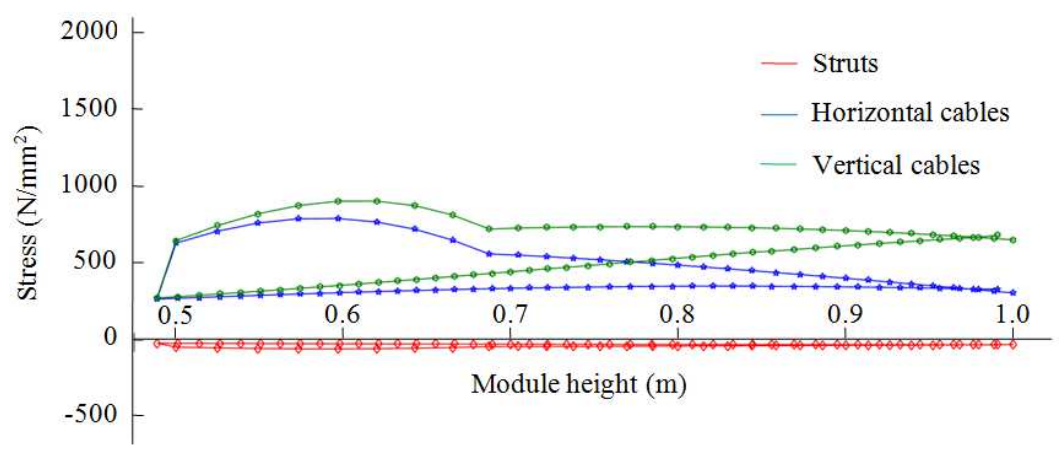

Fig. 4. Evolution of stresses through a folding/unfolding cycle using finite mechanisms assuming truss and cable elements

Figure 4 shows the evolution of stresses in the elements of the module through a folding/unfolding cycle using finite mechanisms and assuming strut as well as cable elements. Since shape transformations are based on a series of finite mechanisms that are controlled (induced and stabilized) by the nine active cables, the stress state in the module can be maintained relatively low compared to design values. Although stresses in the cables vary during folding and unfolding (vertical cables are the primary folding actuators and horizontal cables are the primary unfolding actuators), stresses in the strut elements remain at approximately the same level.

Bending action can be used as an alternative actuation structurally integrated mechanism for unfolding the structure. Consequently, only the three vertical cables have to be actuated to fold and unfold 
the simplex module. Figure 5 shows three snapshots of the shape transformation with module height 0.825 , 0.75 and $0.625 \mathrm{~m}$ respectively. As the three vertical cables shorten during folding, spline elements bend reducing the height of the module.

Figure 6 shows the evolution of stresses in the elements of the module through a folding/unfolding cycle using bending action and three active cables. Since during folding spline elements are bent, stresses in the elements increase with folding. Moreover, strain energy is stored in the structure (primarily in the spline elements) during folding that is then released during unfolding. Vertical cables control thus the unfolding phase by regulating the strain rate in spline elements. Element stresses remain always below design stresses (Table 1). However, higher actuation forces are required for transforming the shape of the module when spline elements are employed.

Employing an integrated bending-active shapecontrol reduces actuation requirements. However, it

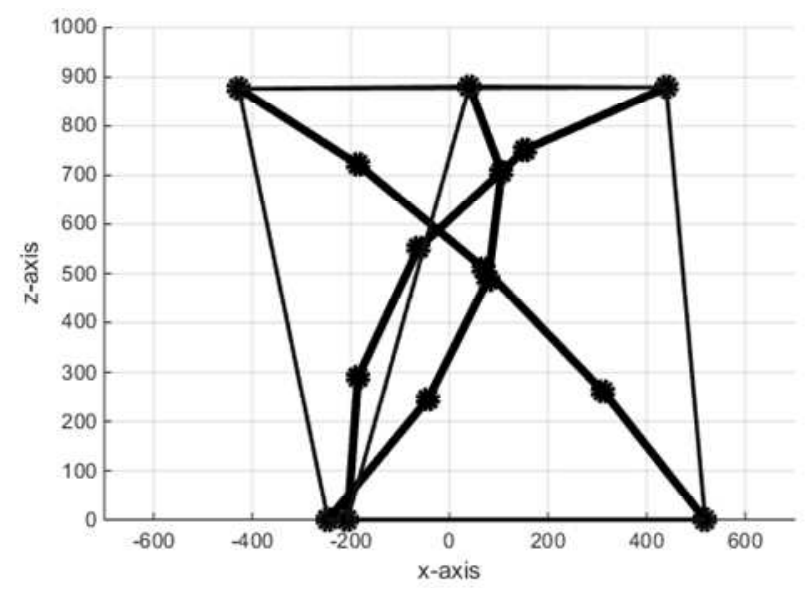

also affects the structural behavior of the module during shape transformations as well as loading. During service, bending stresses can lead to failure at lower loading levels if estimations are done using traditional form-finding and analysis techniques that model tensegrity structures using axial elements (Rhode-Barbarigos and Adriaenssens, 2014). However, if designed appropriately the structure can benefit from bending through stress stiffening effects.

Table 2 compares the average vertical displacement at top nodes for three intermediate configurations with strut and spline elements under a vertical load of $100 \mathrm{~N}$ applied at the same nodes. Due to the bending action of the deformed spline elements, displacements under the vertical load applied at the top three nodes decrease significantly in the spline configuration. The overall stiffness of the structure is thus higher compared to the truss configuration revealing a stress stiffening effect.

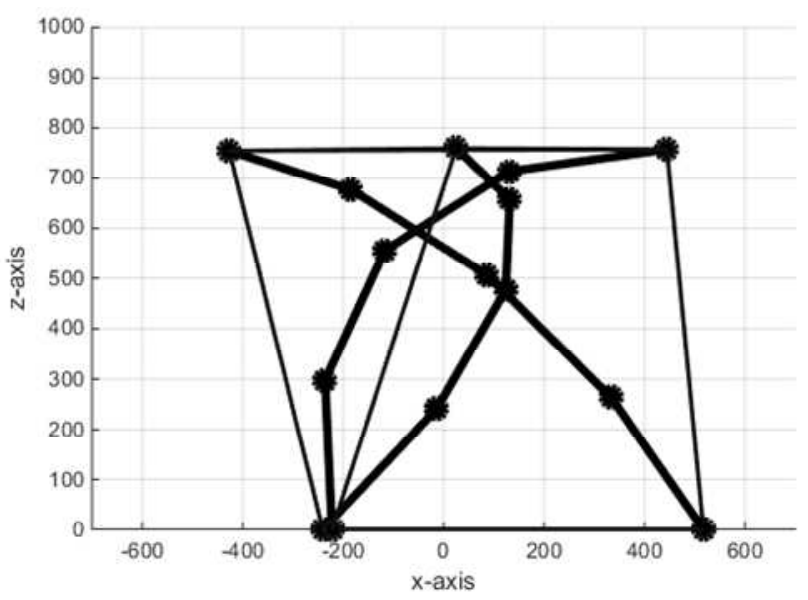

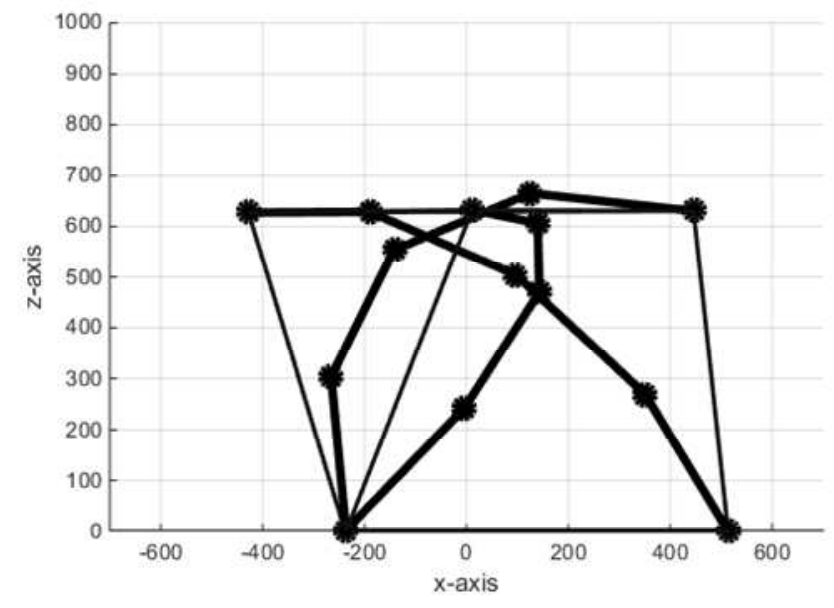

Fig. 5. Side-view snapshots of the shape transformation of the tensegrity module with bending-action assuming spline and cable elements 


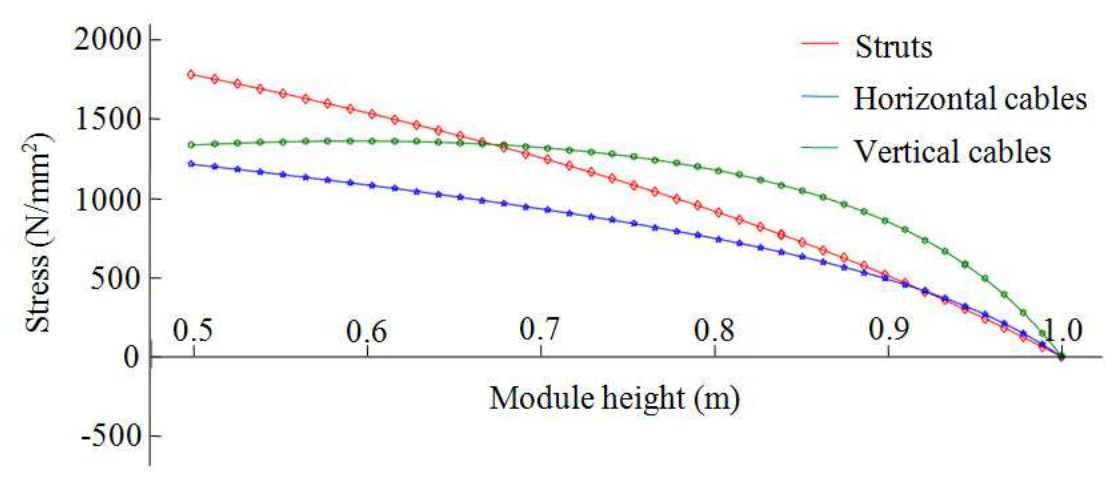

Fig. 6. Evolution of stresses through a folding/unfolding cycle using three active cables and exploring elastic bending deformations in spline elements

Table 2. Average vertical displacement at top nodes for intermediate configurations with truss and spline elements

\begin{tabular}{lll} 
& Vertical displacement at top nodes $(\mathrm{mm})$ & \\
Module height $(\mathrm{m})$ & - Module with truss elements & Module with spline elements \\
\hline 0.625 & 7.3 & 7.7 \\
0.750 & 10.2 & 7.4 \\
0.825 & 14.8 & 7.4 \\
\hline
\end{tabular}

\section{A Structurally Integrated Adaptive Shell Structure}

Shell structures are continuous curved surface structures resisting loading through forces developed in the plane of their surface (membrane stresses). Structural engineers have been investigating and constructing shell structures for decades now (Tedesko, 1937; Nervi, 1955; Candela, 1955; 1963; Isler, 1980). Shell structures offer a great combination of material efficiency and structural performance (Billington, 1982). Thin shell structures have also been studied for their flexibility (Audoly and Pomeau, 2010; Lienhard et al., 2011b), which has been observed in nature (Forterre et al., 2005; Poppinga and Joyeux, 2011) and has great potential for the design of structurally integrated adaptive systems (Lienhard et al., 2011b; Adriaenssens et al., 2014). However, flexible shells involve large displacements and precise kinematics that make the analysis of these systems challenging due to the nonlinearities induced (Calladine, 1989).

The shell structure employed in this paradigm is derived from the shape of the traps of the carnivorous aquatic plant, Aldrovanda vesiculosa (Forterre et al., 2005; Poppinga and Joyeux, 2011). The shell structure is composed of two monolithically connected lobes. Actuation in the shell structure occurs from the uniaxial bending of its central part (midrib) that generates a local distributed load which elastically deforms the lobes pushing them inward (closing of the shell). A small elastic deformation in the central part of the shell results thus in a larger shape change. Moreover, the shell can recover its initial shape once the load has been removed. In the plant structure it is controlled by turgor pressure (Poppinga and Joyeux, 2011), while in the engineered shell structure bending occurs form the application of an external actuation force $F_{\text {closing. }}$ The hinge-less actuation mechanism of the engineered shell is illustrated in Fig. 7 with the external actuation force $F_{\text {closing }}$ represented by a uniformly distributed load directed along the global Z-axis and acting on the surface $S_{c d}$ (highlighted as a bold line).

Numerical simulations using the commercial Finite Element (FE) package Abaqus/CAE (Simulia) are performed to investigate the shape-changing and structural behavior of the shell structure. In this study, the shell structure is initially $0.8 \mathrm{~m}$ long and $0.7 \mathrm{~m}$ wide (segments $\mathrm{AB}$ and EF in Fig. 7, respectively). The shell is simply supported at points A and B. All translations are blocked at point $\mathrm{B}$ while only the displacement along the $\mathrm{X}$-axis is free at point A. The loaded surface $S_{c d}$ has a total area of approximately $0.00732 \mathrm{~m}^{2}$. The actuation force is a distributed load of $10.93 \mathrm{kN} / \mathrm{m}$ on $S_{c d}$ in the Z-direction. To explore elastic deformations, the shell structure is composed of a Carbon Fiber Reinforced Polymer (CFRP). The material properties of CFRP are detailed in Table 3.

Figure 8 shows a series of intermediate configurations during the closing of the shell structure induced by the uniaxial bending of its central part from a gradually increasing force $F_{\text {closing }}$. Figure 9 shows the displacement along the $\mathrm{Y}$-axis occurring in the shell 
structure (on the two lobes) at each actuation step as well as the corresponding maximal Von Mises stresses. The highest value of Von Mises stresses $\left(291.30 \mathrm{~N} / \mathrm{mm}^{2}\right)$ occurs for the fully loaded/actuated shell (step no.10). However, stresses remain largely below design values as they correspond to $42.9 \%$ of the allowable Von Mises stress $\left(678.90 \mathrm{~N} / \mathrm{mm}^{2}\right)$. The kinetic and structural efficiency of the structurally integrated adaptive shell is thus highlighted.

Following the analysis framework proposed in (Lienhard, 2014), the non-linear effect of large displacements induced by actuation on the shell stiffness is numerically determined based on the displacement response of deformed shell configurations to an external loading. The stiffness is valuated as the ratio of applied force over the displacement following Equation 1. The force used to evaluate the stiffness is a uniform surface force of $F_{z_{-} \text {test }}$ of $25 \mathrm{~N} / \mathrm{m}$ applied in the Z-direction towards the interior area of the shell lobes. The stiffness $K_{z}$ is thus estimated as:

$$
K_{z}=F_{z_{-} \text {test }} / U_{z}
$$

where, $F_{z_{-} \text {test }}$ is the surface load along the Z-direction on the inside surface of the shell and $U_{z}$ is the displacement along the $\mathrm{Z}$-axis observed at point $\mathrm{F}$ (Fig. 7). Only the Z-axis component of stiffness is considered in this study. For each load step, the surface force $F_{z_{-} \text {test }}$ is applied to test the stiffness $K_{z}$ and extract the deformed geometry. For the extracted geometry at every step, the surface force $F_{z_{-} \text {test }}$ is then applied again to test its shape-related stiffness $K_{c}$. Figure 10 illustrates the process for the estimation of the shape-related stiffness. In this study, a "stressed" configuration refers to a shell surface that exhibits stresses due to being strained by the actuation loading, while the

"relaxed" configuration corresponds to the extracted geometry of the shell. The relaxed geometry does not exhibit any stresses and strains due to actuation.

Figure 8 shows a series of intermediate configurations during the closing of the shell structure induced by the uniaxial bending of its central part from a gradually increasing force $F_{\text {closing. }}$ Figure 9 shows the displacement along the $\mathrm{Y}$-axis occurring in the shell structure (on the two lobes) at each actuation step as well as the corresponding maximal Von Mises stresses. The highest value of Von Mises stresses $\left(291.30 \mathrm{~N} / \mathrm{mm}^{2}\right)$ occurs for the fully loaded/actuated shell (step no.10). However, stresses remain largely below design values as they correspond to $42.9 \%$ of the allowable Von Mises stress $(678.90 \mathrm{~N} / \mathrm{mm} 2)$. The kinetic and structural efficiency of the structurally integrated adaptive shell is thus highlighted.

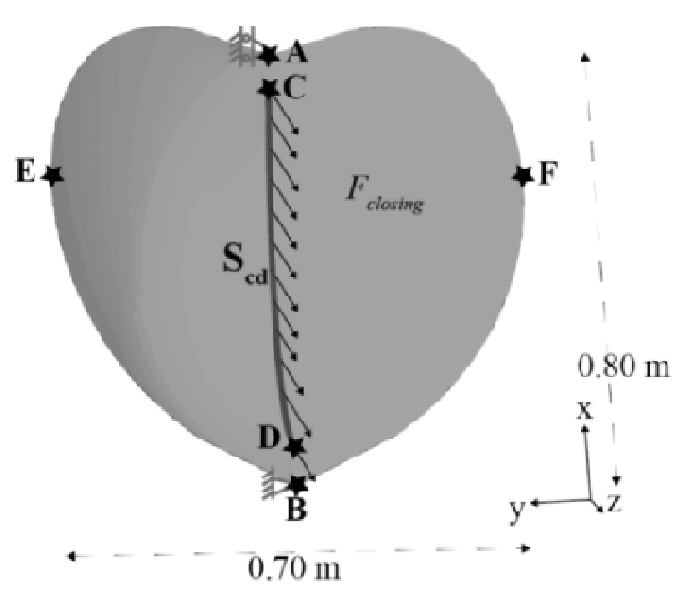

Fig. 7. Illustration of the engineered shell structure and its actuation loading
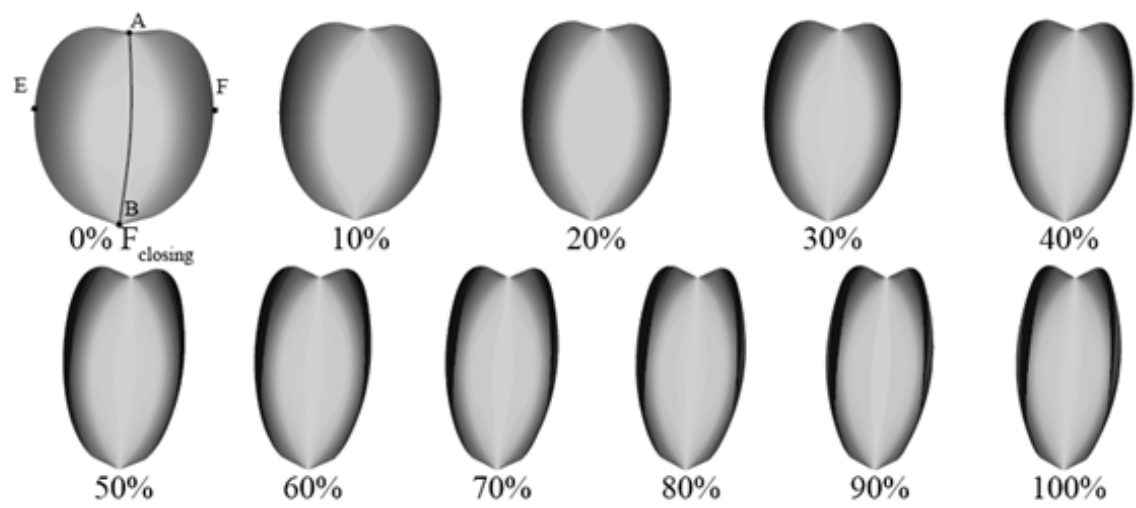

Fig. 8. Series of intermediate form-found equilibrium configurations of the shell structure when actuated by a percentage of the distributed force on its central part 

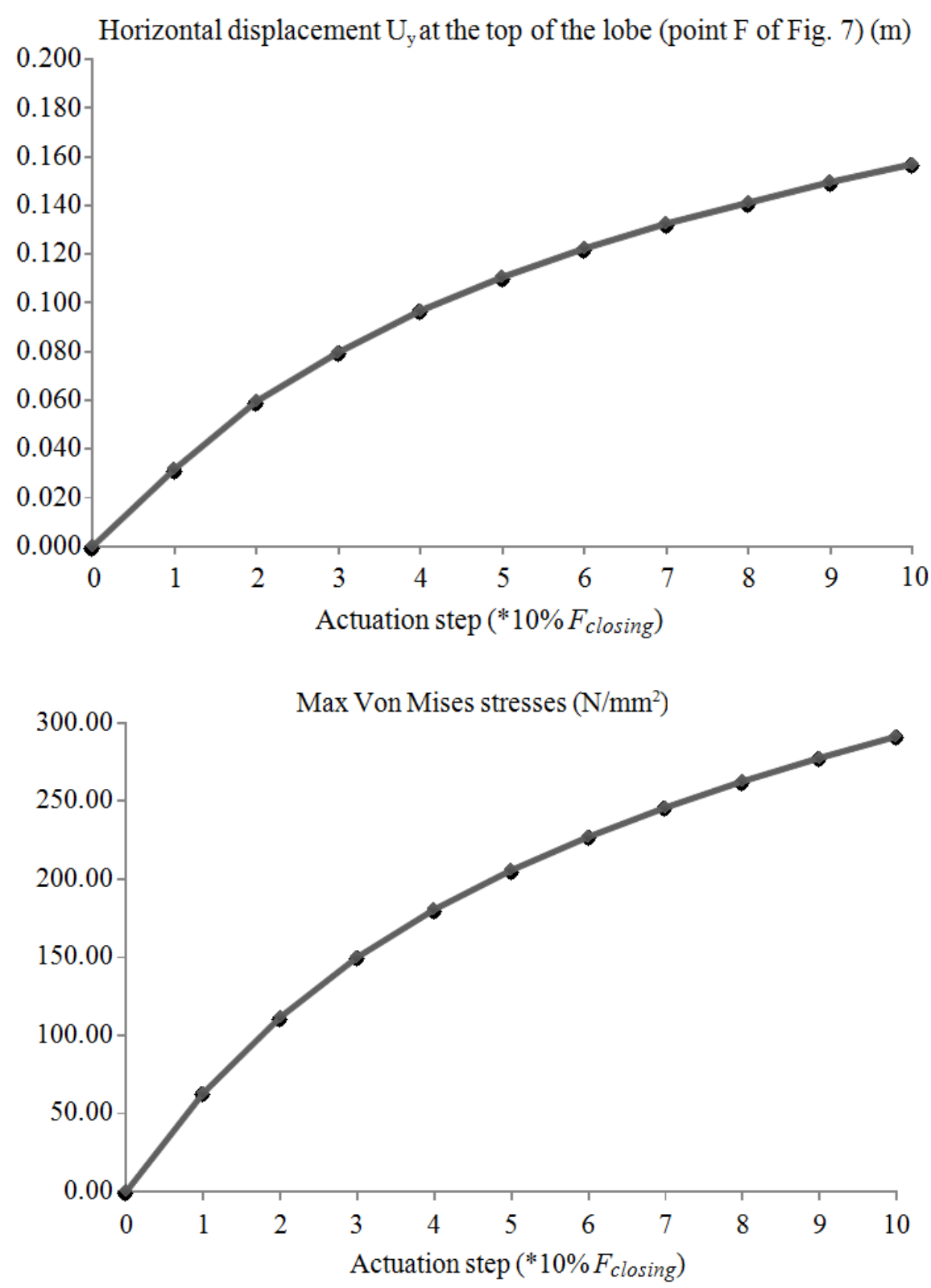

Fig. 9. Horizontal displacements and maximal stresses occurring on the shell structure for each actuation step $(* 10 \%$ of the force $F_{\text {closing }}$ on its central part)

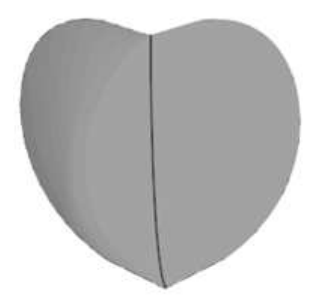

Initial no stresses

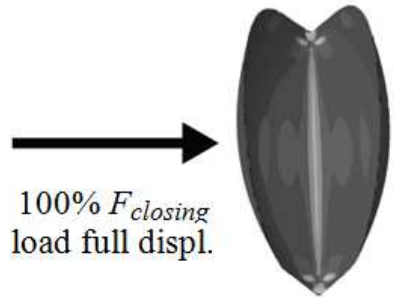

Final stresses

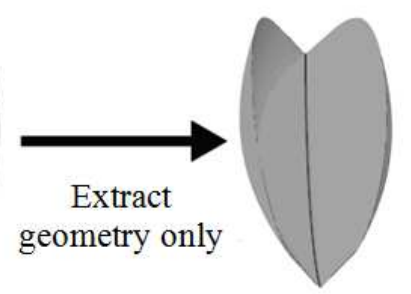

Final extracted relaxed

Fig. 10. Methodology employed for the extraction of the geometry after deformation and the estimation of its "relaxed" stiffness 


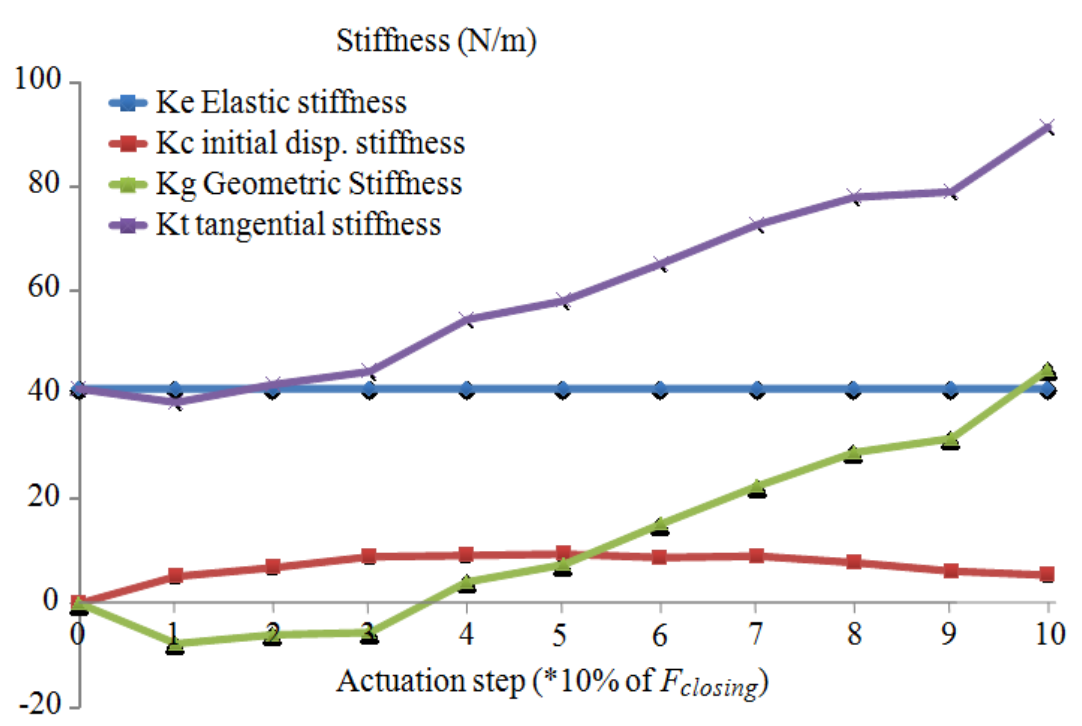

Fig. 11. Progression of the stiffness components of the shell structure during the shape transformation

Table 3. Material properties of Carbon Fiber Reinforced Plastic (CFRP)

\begin{tabular}{|c|c|c|}
\hline Property & & Value \\
\hline \multirow[t]{2}{*}{ Tensile strength } & $\sigma_{\mathrm{x} \text { max tension }}\left(\mathrm{N} / \mathrm{mm}^{2}\right)$ & 553 \\
\hline & $\sigma_{y_{-} \text {max_tension }}\left(\mathrm{N} / \mathrm{mm}^{2}\right)$ & 297 \\
\hline \multirow[t]{2}{*}{ Compressive strength } & $\sigma_{\mathrm{X} \_ \text {max_compression }}\left(\mathrm{N} / \mathrm{mm}^{2}\right)$ & 773 \\
\hline & $\sigma_{y_{\_} \text {max_compression }}\left(\mathrm{N} / \mathrm{mm}^{2}\right)$ & 416 \\
\hline Shear strength & $\tau_{\mathrm{xy} \max }\left(\mathrm{N} / \mathrm{mm}^{2}\right)$ & 63 \\
\hline \multirow[t]{2}{*}{ Young's Modulus } & $\mathrm{E}_{\mathrm{x}}\left(\mathrm{N} / \mathrm{mm}^{2}\right)$ & $91 ' 820$ \\
\hline & $\mathrm{E}_{\mathrm{y}}\left(\mathrm{N} / \mathrm{mm}^{2}\right)$ & $49^{\prime} 550$ \\
\hline Poisson's coefficient & $\mathrm{v}(-)$ & 0.037 \\
\hline Shear modulus & $\mathrm{G}\left(\mathrm{N} / \mathrm{mm}^{2}\right)$ & 4200 \\
\hline
\end{tabular}

In a nonlinear analysis, the tangent matrix $K_{T}$ is defined as Equation 2 to 6:

$K_{T}=K_{E}+K_{C}+K_{G}$

With:

$$
\begin{aligned}
& K_{E}=F_{z_{-} \text {test }} / U_{z_{-} \text {initial }}=c s t \\
& K_{C}=F_{z_{-} \text {test }} / U_{z_{-} \text {initial }}=K_{E} \\
& K_{G}=F_{z_{-} \text {test }} / U_{z^{-}}-\left(K_{E}+K_{C}\right)
\end{aligned}
$$

where, $K_{E}$ is the elastic stiffness, $K_{C}$ is the shape-related stiffness (accounts for the change of geometry/curvature of the structure) and $K_{G}$ is the geometric stiffness. $U_{z \text { initial }}$ is the displacement at points $\mathrm{F}$ and $\mathrm{E}$ (Fig. 7) for the first load step in the Z-direction and $U_{z}$ relaxed is the vertical displacement at the same points in the extracted geometry. In the analysis, stiffness components $K_{C}$ and $K_{G}$ are determined for each load step. The total load $F_{\text {closing }} * S_{C D}$ amounts to $80 \mathrm{~N}$ and is applied in ten steps of magnitude $1 / 10^{*} F_{\text {closing. The constant }} K_{E}$ is given by the response to the first load step. $K_{C}$ results from the difference of the stiffness of the extracted (stress free) shell with the constant $K_{E}$. By applying $F_{z \text { test }}$ to the extracted model, the influence of the stresses developed in the shell up to this load step, is removed from the structural behavior of the model. Finally, $K_{G}$ is obtained by subtracting $K_{E}$ and $K_{C}$ from $K_{T}$.

Figure 11 shows the evolution of the tangent stiffness components during the shape transformation of the shell structure. As expected, the elastic stiffness $K_{E}$ is constant and equal to $K_{T}$ initially. The shape-related stiffness $K_{C}$ increases until step 5 and then continuously decreases. The geometric stiffness $K_{G}$ goes also through two distinct phases: It is negative from steps 1 to 3 and positive from steps 4 to 10 . The first (negative) phase of $K_{G}$ indicates compressive membrane stresses are dominant in the shell structure (Levy and Spillers, 2003), while the second (positive) phase indicates that tensile membrane stresses are governing. Tensile stresses increase the stiffness of the shell structure (tension stiffening) (Levy and Spillers, 2003). During this second phase, $K_{G}$ increases in average $52 \%$ from step to step 
until the final step. Overall, $K_{T}$ is smaller than $K_{E}$ initially because of the large negative contribution of $K_{G}$. However, from step 2 and onwards it becomes larger than $\mathrm{KE}$ as tension stiffening occurs. After load step 4, the geometric stiffness $K_{G}$ controls the behaviour of the tangent stiffness $K_{T}$. Consequently, actuation controls the shape of the shell while also affecting strongly its stiffness and consequently its structural response to external loading.

\section{Conclusion}

In this study, dialectic form finding, a new approach for the design of adaptive structures is proposed. The proposed approach is an extension of the traditional form-finding process with structural as well as shape related constraints and criteria integrated. The resulting structures incorporate adaptation within their structural behavior. They are thus structurally and adaptively efficient systems. Two dialectic form-finding paradigms were presented. The first one is a tensegrity simplex structure. The study of the tensegrity module revealed that the number of actuated elements can be significantly decreased compared to the conventional finite mechanism shape-shifting control, if elastic bending deformations are explored. However, employing activebending elements affects also the structural behavior of the tensegrity structure increasing stresses in elements and the overall stiffness of the structure. In the second example, dialectic form finding was applied to a biomimetic shell structure that opens and closes based on the application of an external actuation load. The study revealed that the efficiency of the hinge-less actuation mechanism and the influence of the external actuation load on the stiffness of the structure. As the actuation loading increase, the geometric stiffness of the structure further augments increasing the overall stiffness of the shell structure. Both examples reveal that actuation and structural performance in dialectic form-found structures are closely related. Therefore, if appropriately designed, the resulting adaptive structures can be both structurally as well as adaptively efficient.

\section{Acknowledgement}

This work was supported in part by the Andlinger Center for Energy and the Environment at Princeton University.

\section{Author's Contributions}

Landolf Rhode-Barbarigos and Sigrid Adriaenssens co-developed the research plan. Landolf RhodeBarbarigos performed also the study on the tensegrity structures and wrote the paper. Victor Charpentier carried out the FE analysis of the adaptive shell structure. Sigrid Adriaenssens and Olivier Baverel coadvised the analysis of the adaptive shell modules. All authors proof read the paper.

\section{Ethics}

The results of the FE analysis of the adaptive shell structure are also part of a conference paper that will be presented at the IASS2015 Annual International Symposium, in Amsterdam, Holland.

\section{References}

Adam, B. and I.F.C. Smith, 2008. Active tensegrity: A control framework for an adaptive civil-engineering structure. Comput. Structures, 86: 2215-2223. DOI: 10.1016/j.compstruc.2008.05.006

Adriaenssens, S., 2008. Feasibility study of medium span spliced spline stressed membranes. Int. J. Space Structures, 23: 243-251.

DOI: $10.1260 / 026635108786959889$

Adriaenssens, S. and M.R. Barnes, 2001. Tensegrity spline beam and grid shell structures. Eng. Structures, 23: 29-36. DOI: 10.1016/S0141-0296(00)00019-5

Adriaenssens, S. and L. Ney, 2007. The piston-stayed bridge: A novel typology for a mobile bridge at tervate, Belgium. Structural Eng. Int., 17: 302-305. DOI: $10.2749 / 101686607782359029$

Adriaenssens, S., P. Block, D. Veenendaal and C.J.K. Williams, 2014a. Shell Structures for Architecture: Form Finding and Optimization. 1st Edn., Taylor and Francis, Routledge, ISBN-10: 1317909380, pp: 340.

Adriaenssens, S., L. Rhode-Barbarigos, A. Kilian, O. Baverel and V. Charpentier et al., 2014b. Dialectic form finding of passive and adaptive shading enclosures. Energies, 7: 5201-5220.

DOI: $10.3390 /$ en7085201

Aldrich, J.B., R.E. Skelton and K. Kreutz-Delgado, 2003. Control synthesis for a class of light and agile robotic tensegrity structures. Proceedings of the American Control Conference, Jun. 4-6, IEEE Xplore Press, pp: 5245-5251.

DOI: 10.1109/ACC.2003.1242560

Audoly, B. and Y. Pomeau, 2010. Elasticity and Geometry: From Hair Curls to the Non-Linear Response of Shells. 1st Edn., Oxford University Press, Oxford, ISBN-10: 0198506252, pp: 600.

Barnes, M.R., 1999. Form finding and analysis of tension structures by dynamic relaxation. Int. J. Space Structures, 14: 89-104. DOI: $10.1260 / 0266351991494722$

Ali, N.B.H., L. Rhode-Barbarigos and I.F.C. Smith, 2011. Analysis of clustered tensegrity structures using a modified dynamic relaxation algorithm. Int. J. Solids Structures, 48: 637-647. DOI: $10.1016 /$ j.ijsolstr.2010.10.029 
Billington, D.P., 1982. Thin shell concrete structures. McGraw-Hill.

Block, P., 2009. Thrust network analysis: Exploring three-dimensional equilibrium. Ph.D. Thesis, Massachusetts Institute of Technology, Cambridge, MA, USA.

Brew, J.S. and D.M. Brotton, 1971. Non-linear structural analysis by dynamic relaxation. Int. J. Numer Methods Eng., 3: 463-83. DOI: 10.1002/nme.1620030403

Calladine, C.R., 1989. Theory of Shell Structures. 1st Edn., Cambridge University Press, ISBN-10: 0521369452, pp: 788.

Candela, F., 1955. Structural applications of hyperbolic paraboloidal shells. J. ACI.

Candela, F., 1963. Felix Candela: The Shell Builder. 1st Edn., Reinhold, New York, pp: 240.

Day, A.S., 1965. An introduction to dynamic relaxation.

Domer, B. and I.F.C. Smith, 2005. An active structure that learns. J. Comput. Civil Eng., 19: 16-24. DOI: 10.1061/(ASCE)0887-3801(2005)19:1(16)

Forterre, Y., J.M. Skotheim, J. Dumais and L. Mahadevan, 2005. How the Venus flytrap snaps. Nature, 433: 421-425. DOI: 10.1038/nature03185

Fox, M. and M. Kemp, 2009. Interactive Architecture. 1st Edn., Princeton Architectural Press, New York, ISBN-10: 1568988362, pp: 256.

Gantes, C.J., 2001. Deployable Structures: Analysis and Design. 1st Edn., WIT Press, Southampton, ISBN-10: 1853126608, pp: 352.

Housner, G.W., L.A. Bergman, T.K. Caughey, A.G. Chassiakos and R.O. Claus et al., 1997. Structural control: Past, present and future. J. Eng. Mechan., 123: 897-971. DOI: 10.1061/(ASCE)0733-9399(1997)123:9(897)

Ingber, D.E., N. Wang and D. Stamenovic, 2014. Tensegrity, cellular biophysics and the mechanics of living systems. Rep. Prog. Phys., 77: 046603-046603. DOI: $10.1088 / 0034-4885 / 77 / 4 / 046603$

Isler, H., 1980. New shapes for shells-Twenty years later, Heinz Isler as structural artist. The art museum, Princeton University, NJ.

Kim, K., A.K. Agogino, D. Moon, L. Taneja and A. Toghyan et al., 2014. Rapid prototyping design and control of tensegrity soft robot for locomotion. Proceedings of the IEEE International Conference on Robotics and Biomimetics, Dec. 5-10, IEEE Xplore Press, Bali, pp: 7-14. DOI: 10.1109/ROBIO.2014.7090299

Korkmaz, S., 2012. A review of active structural control: Challenges for engineering informatics. Comput. Structures, 89: 2113-2132.

DOI: 10.1016/j.compstruc.2011.07.010

Levy, R. and W.R. Spillers, 2003. Analysis of Geometrically Nonlinear Structures. 2nd Edn., Kluwer Academic Publisher, ISBN-10: 1402016549, pp: 272.
Lienhard, J., 2014. Bending-active structures: Formfinding strategies using elastic deformation in static and kinetic systems and the structural potentials therein. PhD These, Universität Stuttgart.

Lienhard, J., S. Schleicher, S. Poppinga T. Masselter and M. Milwich et al., 2011a. Flectofin: A hingeless flapping mechanism inspired by nature. Bioinspir. Biomimet., 6: 045001-045001. DOI: $10.1088 / 1748-3182 / 6 / 4 / 045001$

Lienhard, J., S. Schleicher and J. Knippers, $2011 \mathrm{~b}$. Bending-active structures - research pavilion ICD/ITKE. Proceedings of the International Symposium of the IABSE-IASS Symposium, Taller Longer Lighter, (TLL' 11), London, UK.

Lu, J. and R.E. Skelton, 1998. Optimal hybrid control for structures. Comput. Aided Civil Infrastructure Eng., 13: 405-414. DOI: $10.1111 / 0885-9507.00118$

Motro, R., 2006. Tensegrity: Structural Systems for the Future. 1st Edn., Butterworth-Heinemann, Boston, ISBN-10: 1903996376, pp: 280.

Munghan, I. and J.F. Abel, 2011. Fifty Years of Progress for Shell and Spatial Structures: In Celebration of the 50th Anniversary Jubilee of the IASS (1959-2009). International Association for Shell and Spatial Structures, Madrid, ISBN-10: 190713235X, pp: 492.

Nervi, P.L., 1955. Structures. 1st Edn., Mc-Graw Hill, New York.

Pagitz, M. and J.M. Mirats Tur, 2009. Finite element based form-finding algorithm for tensegrity structures. Int. J. Solids Structures, 46: 3235-3240. DOI: $10.1016 /$ j.ijsolstr.2009.04.018

Pellegrino, S., 2001. Deployable Structures. 1st Edn., Springer, Wien, ISBN-10: 3211836853, pp: 360.

Poppinga, S. and M. Joyeux, 2011. Different mechanics of snap-trapping in the two closely related carnivorous plants Dionaea muscipula and Aldrovanda vesiculosa. Phys. Rev. E, 84: 041928-041928. DOI: 10.1103/PhysRevE.84.041928

Rhode-Barbarigos, L. and S. Adriaenssens, 2014. Investigating the influence of bending in the structural behavior of tensegrity modules using dynamic relaxation. Proceedings of the 5th International Conference on Computational Methods, Jul. 28-30, Cambridge, UK., pp: 1-6.

Rhode-Barbarigos, L., N.B.H. Ali, R. Motro and I.F.C. Smith, 2012a. Mechanism-based approach for the deployment of a tensegrity-ring module. J. Structural Eng. ASCE, 138: 539-548. DOI: 10.1061/(ASCE)ST.1943-541X.0000491

Rhode-Barbarigos, L., N. Bel Hadj Ali, R. Motro and I.F.C. Smith, 2012b. Design aspects of a deployable tensegrity-hollow-rope footbridge. Int. J. Space Structures, 27: 81-96.

DOI: $10.1260 / 0266-3511.27 .2-3.81$ 
Richardson, J.N., S. Adriaenssens, R.F. Coelho and P. Bouillard, 2013. Coupled form-finding and grid optimization approach for single layer grid shells. Eng. Structures, 52: 230-239.

DOI: 10.1016/j.engstruct.2013.02.017

Schek, H.J., 1974. The force density method for form finding and computation of general networks. Comput. Methods Applied Mech. Eng., 3: 115-134. DOI: 10.1016/0045-7825(74)90045-0

Segal, E., L. Rhode-Barbarigos, R.F. Coelho and S. Adriaenssens, 2015. Multi-objective optimization of polyester-rope and steel-rope suspended footbridges. Eng. Structures, 99: 559-567. DOI: $10.1016 /$ j.engstruct.2015.05.024

Siu, S., L. Rhode-Barbarigos, S. Wagner and S. Adriaenssens, 2013. Dynamic relaxation study and experimental verification of dielectric-elastomer minimum-energy structures. Applied Phys. Lett., 103: 171906 . DOI: $10.1063 / 1.4826884$

Sobek, W. and P. Teuffel, 2002. Adaptive lightweight structures. International IASS Symposium, Warsaw, Poland.

Soong, T.T. and G.D. Manolis, 1987. Active structures. J. Structural Eng., 113: 2290-2301. DOI: 10.1061/(ASCE)0733-9445(1987)113:11(2290)

Tedesko, A., 1937. Large concrete shell roof covers ice arena. Eng. News-Rec., 8: 505-510.

Thrall, A.P., S. Adriaenssens, I. Paya-Zaforteza and E. Zoli, 2012a. Linkage-based movable bridges: Design methodology and three novel forms. Eng. Structures, 37: 214-223.

DOI: $10.1016 /$ j.engstruct.2011.12.031
Thrall, A.P., M. Zhu, J. Guest, I. Paya-Zaforteza and S. Adriaenssens, 2012b. Structural optimization of deploying structures composed of linkages. ASCE J. Comput. Civil Eng., 28: 04014010-04014010. DOI: $10.1061 /($ ASCE)CP.1943-5487.0000272

Tibert, A.G. and S. Pellegrino, 2003. Review of formfinding methods for tensegrity structures. Int. J. Space Structures, 18: 209-223. DOI: $10.1260 / 026635103322987940$

Veenendaal, D. and P. Block, 2012. An overview and comparison of structural form finding methods for general networks. Int. J. Solids Structures, 49: 3741-3753. DOI: 10.1016/j.ijsolstr.2012.08.008

Veuve, N., S. Safaei and I.F.C. Smith, 2015. Deployment of a tensegrity footbridge. J. Structural Eng. DOI: 10.1061/(ASCE)ST.1943-541X.0001260

Wada, B.K. and S. Das, 1991. Application of adaptive structure concepts to civil structures, Intelligent structures-monitoring and control. Amsterdam, Elsevier.

Yao, J.T.P., 1972. Concept of structural control. ASCE J. Structural Control, 98: 1567-1574.

Zuk, W. and R.H. Clark, 1970. Kinetic architecture. University of Michigan. 